\title{
ANESTEZIJOS YPATUMAI, ESANT ŠIRDIES VOŽTUVŲ PATOLOGIJAI
}

\author{
Evelina Gudavičiūtè, Raminta Vasiliauskaitė \\ Lietuvos sveikatos mokslu universiteto Medicinos akademija, Medicinos fakultetas
}

Raktažodžiai: anestezija, širdies chirurgija, širdies vožtuvų patologijos.

\section{Santrauka}

Širdies vožtuvų ligų paplitimas ir sunkumas didejja kartu su amžiumi, todèl senėjančiose populiacijose didèja širdies vožtuvų operacijų poreikis. Esant skirtingai vožtuvų patologijai, keliami skirtingi hemodinamikos stebėsenos tikslai: esant aortos vožtuvo stenozei, rekomenduojama vengti hipovolemijos, kai yra aortos ir mitralinio vožtuvo nesandarumas - vengti hipervolemijos. Mitralinio vožtuvo stenozès atvejais vengtina tiek hipovolemija, tiek hipervolemija. İ šią literatūros apžvalgą buvo ịtraukti moksliniai šaltiniai, kuriuose nagrinejami anestezijos ypatumai ir aptariami hemodinamikos stebėsenos tikslai, esant skirtingai širdies vožtuvų patologijai. Literatūros šaltinių paieška buvo vykdoma medicinos duomenų bazėse PubMed, UpToDate, Medscape. Apžvalgai naudoti 2015-2020 metais spausdinti straipsniai anglų kalba, atitinkantys apžvalgos kriterijus. Apžvalgos rezultatai parodè, kad esant skirtingoms vožtuvų patologijoms, skiriasi tikslinis širdies susitraukimų dažnis. Etomidatas gali būti pasirinktas kaip indukcijos agentas pacientams, kuriems pasireiškia kardiogeninis šokas, hemodinaminis nestabilumas, kritinè vainikinių arterijų liga, sunki aortos stenozė ar sunki kardiomiopatija. Pacientams, sergantiems kritine aortos stenoze arba esant sunkiai skilveliu disfunkcijai, reikalingas ypač atsargus mažesnių dozių titravimas. Dažnas anestezijos gylio koregavimas yra būtinas, atliekant širdies chirurgines procedūras.

\section{Ivadas}

Bendras vožtuvų širdies ligų paplitimas ir sunkumas didèja su amžiumi [1]. Išsivysčiusiose šalyse dažniausiai pasitaikantys vožtuvų pažeidimai yra aortos stenozė (kartu su triburio ar dviburio vožtuvų pažaida) ir mitralinio vožtuvo nesandarumas (regurgitacija) [1]. Pastarasis galimas dèl pirminių priežasčių, tokių kaip degeneracinè liga, arba antrinių - funkcinių priežasčių, tokių kaip išeminè širdies liga ar kardiomiopatija [1]. Pacientams vienodai dažnai vienu būna ir stenoze, ir regurgitacija, veikianti tą patị širdies vožtuvą [1]. Be to, vienu metu dažnai būna pažeisti daugiau nei vienas vožtuvai [1], todèl ši problema yra kompleksiška, nes esant skirtingai vožtuvų patologijai skiriasi hemodinamikos tikslai širdies operacijos metu, o esant kelioms vožtuvų patologijoms, sudètinga užtikrinti stabilią hemodinamiką. Šiame straipsnyje pateikiami apibendrinti pagrindiniai hemodinamikos tikslai širdies operacijų metu pacientams su aortos bei mitralinio vožtuvo stenoze ir nesandarumu bei širdies chirurgijos anestezijos bendrieji principai.

Tyrimo tikslas - atlikti literatūros apžvalgą ir nustatyti pagrindinius hemodinamikos tikslus širdies operacijų metu pacientams su aortos bei mitralinio vožtuvo stenoze ir nesandarumu, aptarti širdies chirurgijos anestezijos bendruosius principus.

\section{Tyrimo medžiaga ir metodai}

Atlikta mokslinès literatūros apžvalga. Literatūros šaltinių paieška buvo vykdoma medicinos duomenų bazėse $\mathrm{Pu}-$ bMed, UpToDate, Medscape. Apžvalgai naudoti 2015-2020 metais spausdinti straipsniai anglų kalba, atitinkantys apžvalgos temą. Paieška buvo vykdoma naudojant reikšminius raktinius žodžius bei jų derinius: anesthesia, aortic valve stenosis, mitral valve stenosis, mitral valve regurgitation, aortic valve regurgitation.

\section{Tyrimo rezultatai}

Aortos angos stenozė (AS) yra ypač pavojinga vožtuvų patologija . Amerikos širdies asociacijos gairèse sunki AS apibrezžiama kaip aortos vožtuvo plotas $\leq 1 \mathrm{~cm} 2$, vidutinis gradientas $\geq 40 \mathrm{~mm} \mathrm{Hg}$ ir maksimalus greitis $\geq 4 \mathrm{~m} / \mathrm{s}$ [4]. Priešoperaciniai aspektai: atliekant preanestezinę konsultaciją ir interpretuojant tyrimų rezultatus, būtina atkreipti dėmesị i AS sunkumą, aortos regurgitaciją, kitą širdies vožtuvų patologiją, kairiojo ir dešiniojo skilvelio disfunkciją ir vainikinių arterijų ligą [1]. Jei operacija skubi, gali būti 
vartojamos nedidelès trumpo veikimo benzodiazepinų (pvz., 0,5-1 mg midazolamo ir (arba) 25-50 mikrogramų fentanilio) papildomos dozės, siekiant sumažinti reakciją ị stresą (pvz., ịterpiant centrinị veninị kateterị) [1]. Neįrodyta, kad pacientams, sergantiems aortos stenoze, atliekama neširdinė operacija sukelia didesnę mirštamumo riziką, tačiau nepageidaujamų širdies ir kraujagyslių reiškinių dažnis yra žymiai didesnis, palyginti su

1 lentelè. Pagrindiniai hemodinamikos valdymo tikslai pacientams, sergantiems aortos stenoze [1].

\begin{tabular}{|c|c|c|c|}
\hline $\begin{array}{l}\text { Hemodi- } \\
\text { naminiai } \\
\text { tikslai }\end{array}$ & Vengti & Stebėti & Intervencijos \\
\hline $\begin{array}{l}\text { Sinusinis } \\
\text { ritmas }\end{array}$ & $\begin{array}{l}\text { Vengti priešir- } \\
\text { džių virpėjimo, } \\
\text { supraventriku- } \\
\text { linės tachikar- } \\
\text { dijos (SVT) } \\
\text { Vengti AV } \\
\text { sinchronijos } \\
\text { praradimo }\end{array}$ & $\begin{array}{l}5 \text { krypčių } \\
\text { EKG }\end{array}$ & $\begin{array}{l}\text { Valdyti naujai atsiradusi prieširdžių } \\
\text { virpejjimą ar SVT: kontroliuoti ŠSD } \\
\text { Valdyti AV sinchronijos praradimą: } \\
\text { sumažinkite inhaliacinio anestetiko } \\
\text { dozę, palaikydami normalų sisteminị } \\
\text { AKS (pvz., panaudojant efedriną ar } \\
\text { norepinefriną) }\end{array}$ \\
\hline $\begin{array}{l}\text { Normalus } \\
\text { ŠSD }(60 \mathrm{iki} \\
80 \mathrm{k} / \mathrm{min})\end{array}$ & $\begin{array}{l}\text { Vengti tachi- } \\
\text { kardijos } \\
\text { Vengti bradi- } \\
\text { kardijos }\end{array}$ & $\begin{array}{l}5 \text { krypčiu } \\
\text { EKG } \\
\text { Pulsoksi- } \\
\text { metrija su } \\
\text { mato m a } \\
\text { b a n g o s } \\
\text { forma }\end{array}$ & $\begin{array}{l}\text { Užkirsti kelią tachikardijai, užtikrinant } \\
\text { adekvatų anestezijos ir nuskausminimo } \\
\text { gylị } \\
\text { Tachikardiją, susijusią su hipotenzija, } \\
\text { valdyti infuzoterapija arba vazokons- } \\
\text { triktoriumi (pvz. norepinefrinu) } \\
\text { Šrirdies ritmo sulėtinimui, jei reikia, } \\
\text { galima panaudoti beta blokatorius }\end{array}$ \\
\hline $\begin{array}{l}\text { Palaikyti } \\
\text { pokrūvị }\end{array}$ & $\begin{array}{l}\text { Vengti hipoten- } \\
\text { zijos } \\
\text { Vengti spinali- } \\
\text { nès nejautros } \\
\text { Vengti sunkios } \\
\text { ar nuolatinès } \\
\text { hipertenzijos }\end{array}$ & $\begin{array}{l}\text { Intraarte- } \\
\text { rinis krau- } \\
\text { jospūdis }\end{array}$ & $\begin{array}{l}\text { Hipotenzijos valdymas: naudoti va- } \\
\text { zokonstriktorių (pvz., norepinefriną). } \\
\text { Apsvarstyti prevencinę mažą vazo- } \\
\text { konstriktoriaus (pvz., norepinefrino) } \\
\text { infuzijos dozę indukcijos metu } \\
\text { Hipertenzijos valdymas: jei yra hiper- } \\
\text { tenzija su padidejusiu ŠSD, naudoti } \\
\text { beta blokatorių (pvz., Metoprololį). } \\
\text { Jei reikia, kiti antihipertenziniai vaistai } \\
\text { gali būti lètai titruojami laipsniškomis } \\
\text { dozėmis }\end{array}$ \\
\hline $\begin{array}{l}\text { Palaikyti } \\
\text { prieškrūvị }\end{array}$ & $\begin{array}{l}\text { Vengti hipovo- } \\
\text { lemijos }\end{array}$ & $\begin{array}{l}\text { Itvertinti } \\
\text { kliniking̣ } \\
\text { atsaką ì } \\
\text { skys či uc } \\
\text { boliusus }\end{array}$ & $\begin{array}{l}\text { Palaikyti intravaskulinị tūrị } \\
\text { Greitas gaivinimas dėl kraujavimo }\end{array}$ \\
\hline $\begin{array}{l}\text { Palaikyti } \\
\text { susitrauki- } \\
\text { mus }\end{array}$ & $\begin{array}{l}\text { Vengti vaistų } \\
\text { dozių, suke- } \\
\text { liančių reikš- } \\
\text { mingą mio- } \\
\text { kardo depresiją }\end{array}$ & $\begin{array}{l}\text { Hemodina- } \\
\text { mika }\end{array}$ & $\begin{array}{l}\text { Jei reikalingas nuolatinis inotropinis } \\
\text { palaikymas, pirmenybè teikiama no- } \\
\text { repinefrinui }\end{array}$ \\
\hline
\end{tabular}

pacientais, kuriems nèra aortos stenozès [3]. Didelès apimties ne širdies operaciją rekomenduojama atidèti, kol aortos stenozè bus koreguota atliekant chirurginę ar perkutaninę intervenciją (1 lentelè) [5].

Mitralinio vožtuvo stenozė yra patologinè būklè, kai vožtuvų burių judrumas paprastai būna sumažèjęs dèl kalcifikacijos [6]. Dèl to vožtuvas tinkamai neatsidaro, pasikeičia kraujo tekèjimas iš kairiojo prieširdžio ị kairịji skilveli, sumažeja širdies pumpavimo efektyvumas [6]. Mitralinio vožtuvo kalcifikacijos rizikos veiksniai yra vyresnis amžius, moteriška lytis, lètinè inkstų liga ir ligos, predisponuojančios kairiojo skilvelio hipertrofiją (pvz., arterinè hipertenzija ir aortos stenozè) (2 lentelè) [7].

Aortos vožtuvo nesandarumas. Lètinị aortos vožtuvo nesandarumą sukelia kairiojo skilvelio (KS) tūrio perkrova, palaipsniui vystosi ekscentrinis KS išsiplètimas [8]. Nors pacientams, sergantiems vidutinio sunkumo ar sunkiu aortos vožtuvo nesandarumu (AVN), biventrikulinè funkcija paprastai lieka nepakitusi, pažengusiose stadijose gali vystytis dilatacinè kardiomiopatija, kairiojo skilvelio nepakankamumas, pasireiškiantis laipsnišku išstūmimo frakcijos sumažejimu [8]. Pastebèta, kad dèl sunkaus lètinio AVN atsiranda žemas diastolinis kraujospūdis, kuris gerai toleruojamas, nebent prasideda gretutinė vainikinių arterijų liga[1].

Ūminis aortos vožtuvo nesandarumas atsiranda dèl aortos disekcijos ar endokardito, išsivysto greita kairiojo skilvelio perkrova tūriu. Staiga gali prasidèti sunkus širdies nepakankamumas ir progresuoti iki kardiogeninio šoko [8]. Gydymas reikalauja intensyvaus būklès valdymo ir skubios širdies chirurginès intervencijos [9]. Perioperaciné rizika yra didele [8]. Intraaortinio baliono siurblio (IABP) naudojimas yra draudžiamas, nes tai padidintų aortos vožtuvo regurgitaciją ir KS išsiplètimą [1].

Mitralinio vožtuvo nesandarumas. Lètinis mitralinio vožtuvo nesandarumas sukelia kairiojo prieširdžio ir kairiojo skilvelio tūrio perkrovą, kartu su KS ir KP išsiplètimu, padidejjusiu KP slègiu ir prieširdžių ritmo sutrikimais (prieširdžiu virpėjimas) [1]. 
Plaučių kraujagyslių pasipriešinimas (PVR) ir plaučių arterijos slègis gali žymiai padidèti pacientams, sergantiems lètiniu sunkiu $\mathrm{MN}$ [1].

Ūminị mitralinio vožtuvo nesandarumą (ŪMN) gali sukelti plyšusi chorda (dèl degeneracinès mitralinio vožtuvo ligos ir infekcinio endokardito), papiliarinio raumens plyšimas (miokardo infarktas) arba papiliarinio raumens poslinkis dèl miokardo infarkto ar išemijos [1]. ŪMN atveju būtina neatidèliotina medicininè ir chirurgine pagalba [10]. Pacientams paprastai būna išreikštas sunkus dekompensuotas širdies nepakankamumas dèl staigios perkrovos slègiu ir tūriu [10]. Staiga išsiplètęs kairysis prieširdis gali sukelti žaibinę plaučių edemą, ūminị dešiniosios širdies nepakankamumą ir kardiogeninị šoką [1]. Pacientams, sergantiems ŪMN, prieš operaciją (arba prieš vainikinių arterijų intervenciją) gali būti panaudojamas intraaortinis balioninis siurblys (IABP), siekiant sumažinti kairiojo skilvelio perkrovą ir pagerinti vainikinių arterijų kraujotaką (3 lentelè) [1].

Širdies chirurgijos anestezija: bendrieji principai

Premedikacija. Galima skirti nedideles papildomas dozes trumpalaikio veikimo benzodiazepino (pvz., 1-2 mg midazolamo) ir (arba) opioido (pvz., 50 mikrogramų fentanilio) [1]. Daugeliui širdies chirurgijos pacientų reikalingas ypač atsargus mažesnių dozių titravimas, pavyzdžiui, tiems, kuriems yra kritinè aortos stenozė arba sunki skilvelių disfunkcija [2].

Bendrinės anestezijos indukcija. Dažniausiai anestezijos indukcijai širdies chirurgijos pacientams naudojamos mažos hipnotiku dozès, subalansuotos su maža opioidụ ir inhaliacinių anestetikų doze [2]. Pavyzdžiui, maža propofolio dozè (pvz., 0,5-1,5 mg / $\mathrm{kg}$ ) gali būti skiriama kartu su vidutine 2-4 $\mathrm{mcg} / \mathrm{kg}$ fentanilio ir neuromuskulinio blokatoriaus doze [2].

Dèl mažiausio hemodinaminio šalutinio poveikio etomidatas gali būti pasirinktas kaip indukcijos agentas pacientams, kuriems pasireiškia kardiogeninis šokas, hemodinaminis nestabilumas, kritinè vainikiniu arterijų liga, sunki aortos stenozė ar sunki kardiomiopatija [11].

Anestezijos palaikymas. Bendra anestezija paprastai palaikoma inhaliaciniu anestetiku, nors gali būti naudojama bendra intraveninès anestezijos (TIVA) technika arba inhaliacinių ir intraveninių (IV) agentų derinys [2].

2 lentelè. Pagrindiniai hemodinamikos valdymo tikslai pacientams, sergantiems mitralinio vožtuvo stenoze [1] (tęsinys kitame puslapyje).

\begin{tabular}{|c|c|c|c|}
\hline $\begin{array}{l}\text { Hemodinami- } \\
\text { kos stebėsenos } \\
\text { tikslai }\end{array}$ & Vengti & Stebėti & Intervencijos \\
\hline Sinusinis ritmas & $\begin{array}{l}\text { Vengti priešir- } \\
\text { džių virpejjimo, } \\
\text { supraventrikuli- } \\
\text { nès tachikardijos } \\
\text { (SVT) }\end{array}$ & 5 krypčių EKG & $\begin{array}{l}\text { Valdyti naujai atsiradusị } \\
\text { prieširdžių virpejjimą ar } \\
\text { SVT: kontroliuoti ŠSD } \\
\text { Jei reikia - kardioversija }\end{array}$ \\
\hline $\begin{array}{l}\text { Lètesnis arba } \\
\text { normalaus ŠSD } \\
(50 \text { iki } 70 \mathrm{k} / \\
\text { min.) }\end{array}$ & $\begin{array}{l}\text { Vengti tachikar- } \\
\text { dijos (gali sukelti } \\
\text { plaučių edema) } \\
\text { Vengti sunkios } \\
\text { bradikardijos } \\
<50 \mathrm{k} / \mathrm{min} .\end{array}$ & $\begin{array}{l}5 \text { krypčių EKG } \\
\text { Pulsoksimetrija } \\
\text { su matoma ban- } \\
\text { gos forma }\end{array}$ & $\begin{array}{l}\text { Užkirsti kelią tachikardijai, } \\
\text { užtikrinant adekvatų aneste- } \\
\text { zijos ir nuskausminimo gyli } \\
\text { Tachikardiją, susijusią su } \\
\text { hipotenzija, valdyti infuzo- } \\
\text { terapija arba vazokonstrik- } \\
\text { toriumi (pvz. norepinefrinu) } \\
\text { Šrdies ritmo suletinimui, } \\
\text { jei reikia, galima panaudoti } \\
\text { beta blokatorius }\end{array}$ \\
\hline $\begin{array}{l}\text { Palaikyti po- } \\
\text { krūvị }\end{array}$ & $\begin{array}{l}\text { Vengti hipoten- } \\
\text { zijos } \\
\text { Vengti spinalinès } \\
\text { nejautros }\end{array}$ & $\begin{array}{l}\text { Intraarterinis } \\
\text { kraujospūdis }\end{array}$ & $\begin{array}{l}\text { Hipotenzijos valdymas: } \\
\text { naudoti vazokonstriktoriu } \\
\text { (pvz., norepinefriną) }\end{array}$ \\
\hline \multirow[t]{2}{*}{$\begin{array}{l}\text { Adekvatus } \\
\text { prieškrūvis }\end{array}$} & $\begin{array}{l}\text { Vengti hipervole- } \\
\text { mijos }\end{array}$ & $\begin{array}{l}\text { Klinikinè eiga ir } \\
\text { oksigenacija } \\
\text { Žaibiškos plau- } \\
\text { čių edemos at- } \\
\text { siradimas (gali } \\
\text { atsirasti kaip } \\
\text { ūmus kosulys } \\
\text { ir hipoksemija } \\
\text { prabudusiam pa- } \\
\text { cientui) }\end{array}$ & $\begin{array}{l}\text { Plaučių edemos gydymas: } \\
\text { nedelsiant gydyti hipokse- } \\
\text { miją, susijusią su plaučių } \\
\text { edema: skirti } 100 \% \text { deguo- } \\
\text { nies, PEEP }\end{array}$ \\
\hline & $\begin{array}{l}\text { Vengti hipovole- } \\
\text { mijos }\end{array}$ & $\begin{array}{l}\text { Ivertinti klinikinị } \\
\text { atsaką i skysčių } \\
\text { boliusus }\end{array}$ & $\begin{array}{l}\text { Palaikyti intravaskulinị tūrị } \\
\text { Greitas gaivinimas dèl } \\
\text { kraujavimo }\end{array}$ \\
\hline $\begin{array}{l}\text { Palaikyti deši- } \\
\text { niojo skilvelio } \\
\text { susitraukimus }\end{array}$ & \begin{tabular}{|l|} 
Vengti vaistų do- \\
zių, sukeliančių \\
reikšmingą mio- \\
kardo depresiją
\end{tabular} & Hemodinamika & $\begin{array}{l}\text { Jei reikalingas inotropinis } \\
\text { palaikymas, gali būti nau- } \\
\text { dojamas dobutaminas, jei } \\
\text { palaikoma sisteminis AKS; } \\
\text { gali prireikti mažos epinef- } \\
\text { rino dozės }\end{array}$ \\
\hline
\end{tabular}




\begin{tabular}{|c|c|c|c|}
\hline $\begin{array}{l}\text { Sumažinti plau- } \\
\text { čių kraujagyslių } \\
\text { pasipriešinimą } \\
\text { (optimizuoti } \\
\text { deguonies kiekį } \\
\text { ir ventiliavimą) }\end{array}$ & $\begin{array}{l}\text { Vengti hipokse- } \\
\text { mijos } \\
\text { Vengti hiperkar- } \\
\text { bijos }\end{array}$ & $\begin{array}{l}\text { Pulsoksimetrija } \\
\text { su matoma ban- } \\
\text { gos forma } \\
\text { Kapnometrija } \\
\text { Arterinių kraujo } \\
\text { dujų analizė, jei } \\
\text { yra intraarterinis } \\
\text { kateteris }\end{array}$ & $\begin{array}{l}\text { Sumažinti hipoksemijos ir } \\
\text { hiperkarbijos riziką: skirti } \\
\text { papildomą deguonį, užti- } \\
\text { krinti pakankamą ventilia- } \\
\text { ciją }\end{array}$ \\
\hline
\end{tabular}

Atliekant širdies chirurgines procedūras, anestezijos poreikis labai skiriasi, todèl būtina dažnai koreguoti anestezijos gylị. Pavyzdžiui, per pirmą pjūvị, ypač sternotomijos metu, gali pasireikšti stiprus skausmas ir endogeninio katecholamino išsiskyrimas, todèl, norint išvengti tachikardijos ir hipertenzijos, reikia koreguoti bendrosios anestezijos gylị [2].

3 lentelè. Pagrindiniai hemodinamikos valdymo tikslai pacientams, sergantiems mitralinio ir aortos vožtuvo nesandarumu [1].

\begin{tabular}{|c|c|c|c|}
\hline $\begin{array}{l}\text { Hemodinami- } \\
\text { niai tikslai }\end{array}$ & Vengti & Stebėti & Intervencijos \\
\hline $\begin{array}{l}\text { Normalus arba } \\
\text { pagreitèjęs } \\
\text { ŠSD }(80 \text { iki } \\
100 \mathrm{k} / \mathrm{min})\end{array}$ & $\begin{array}{l}\text { Vengti bradi- } \\
\text { kardijos }\end{array}$ & $\begin{array}{l}5 \text { krypčių EKG } \\
\text { Pulsoksimetrija } \\
\text { su matoma ban- } \\
\text { gos forma }\end{array}$ & $\begin{array}{l}\text { Bradikardijos gydymas: efedrinas } \\
\text { Jei reikia, infuzuoti mažas dopa- } \\
\text { mino ar epinefrino dozes }\end{array}$ \\
\hline $\begin{array}{l}\text { Normalus arba } \\
\text { mažas pokrū- } \\
\text { vis }\end{array}$ & $\begin{array}{l}\text { Vengti hiper- } \\
\text { tenzijos }\end{array}$ & $\begin{array}{l}\text { Intraarterinis } \\
\text { kraujospūdis }\end{array}$ & 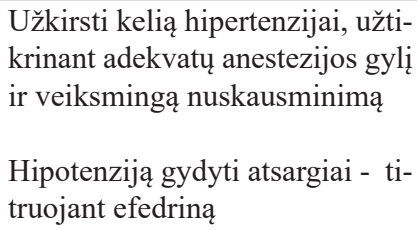 \\
\hline $\begin{array}{l}\text { Normalus arba } \\
\text { mažas prieš- } \\
\text { krūvis }\end{array}$ & $\begin{array}{l}\text { Vengti hiper- } \\
\text { volemijos }\end{array}$ & $\begin{array}{l}\text { Ivertinti klinikinị } \\
\text { atsaką i mažus } \\
\text { skysčių boliusus }\end{array}$ & $\begin{array}{l}\text { Ribota infuzoterapija } \\
\text { Nitroglicerinas ị/v dèl tūrio per- } \\
\text { krovos }\end{array}$ \\
\hline $\begin{array}{l}\text { Palaikyti susi- } \\
\text { traukimus }\end{array}$ & $\begin{array}{l}\text { Vengti vaistų } \\
\text { dozių, su- } \\
\text { ke lia n č i ų } \\
\text { reikšmingą } \\
\text { miokardo de- } \\
\text { presiją }\end{array}$ & Hemodinamika & $\begin{array}{l}\text { Jei reikalingas inotropinis pa- } \\
\text { laikymas, gali būti naudojamas } \\
\text { dobutaminas arba epinefrinas } \\
\text { mažomis dozėmis }\end{array}$ \\
\hline
\end{tabular}

\section{Išvados}

1. Esant aortos vožtuvo stenozei, tikslinis širdies susitraukimų dažnis $60-80 \mathrm{k} / \mathrm{min}$, mitralinio vožtuvo stenozei $50-70 \mathrm{k} / \mathrm{min}$, o aortos ir mitralinio vožtuvo nesandarumui $80-100 \mathrm{k} / \mathrm{min}$.

2. Esant aortos vožtuvo stenozei, rekomenduojama vengti hipovolemijos; kai yra aortos ir mitralinio vožtuvo nesandarumas - vengti hipervolemijos. Jei yra mitralinio vožtuvo stenozè - vengti ir hipovolemijos, ir hipervolemijos.

3. Etomidatas gali būti pasirinktas kaip indukcijos agentas pacientams, kuriems pasireiškia kardiogeninis šokas, hemodinaminis nestabilumas, kritinè vainikinių arterijų liga, sunki aortos stenozè ar sunki kardiomiopatija.

4. Pacientams, sergantiems kritine aortos stenoze arba esant sunkiai skilvelių disfunkcijai, reikalingas ypač atsargus mažesnių dozių titravimas.

5. Atliekant širdies chirurgines procedūras, anestezijos poreikis labai skiriasi, todèl būtina dažnai koreguoti anestezijos gyli.

\section{Literatūra}

1. D'Ambra MN, Diprose P. Anesthesia for cardiac valve surgery. UpToDate 2021.

2. Barbeito A, Bull AEJ. Anesthesia for cardiac surgery: general principles. UpToDate 2021.

3. Kwok CS, Bagur R, Rashid M, Lavi R, Cibelli M, de Belder MA, Moat N, Hildick-Smith D, Ludman P, Mamas MA. Aortic stenosis and non-cardiac surgery: a systematic review and meta-analysis. International Journal Cardiology 2017;240:145-153.

https://doi.org/10.1016/j.ijcard.2017.04.037

4. Tribouilloy C, Rusinaru D, Bohbot Y, Maréchaux S, Vanoverschelde JL, EnriquezSarano M. How should very severe aortic stenosis be defined in asymptomatic individuals? Journal American Heart Association 2019;8(3):e011724.

https://doi.org/10.1161/JAHA.118.011724

5. Pislaru SV, Abel MD, Schaff HV, Pellikka PA. Aortic stenosis and noncardiac surgery: managing the risk. Current Problems Cardiology 2015;40(11):483-503.

https://doi.org/10.1016/j.cpcardiol.2015.06.003

6. Meschini V, Viola F, Verzicco R. Modeling mitral valve stenosis: a parametric study on the stenosis severity level. Journal Biomechanics 2019;84:218-226.

https://doi.org/10.1016/j.jbiomech.2019.01.002

7. Nishimura RA, Vahanian A, Eleid MF, Mack MJ. Mitral valve disease--current management and future challenges. Lancet 2016;387(10025):1324-1334.

https://doi.org/10.1016/S0140-6736(16)00558-4

8. Akinseye OA, Pathak A, Ibebuogu UN. Aortic valve regurgitation: a comprehensive review. Current Problems Cardiology 2018:43(8):315-334.

https://doi.org/10.1016/j.cpcar- 
diol.2017.10.004

9. Flint N, Wunderlich NC, Shmueli H, Ben-Zekry S, Siegel RJ, Beigel R. Aortic Regurgitation. Current Cardiology Reports, 2019;21(7):65.

https://doi.org/10.1007/s11886-019-1144-6

10. Watanabe N. Acute mitral regurgitation. Heart 2019;105(9): 671-677.

https://doi.org/10.1136/heartjnl-2018-313373

11. Hannam JA, Mitchell SJ, Cumin D, Frampton C, Merry AF, Moore MR, Kruger CJ. Haemodynamic profiles of etomidate vs propofol for induction of anaesthesia: a randomised controlled trial in patients undergoing cardiac surgery. British Journal Anaesthesia, 2019;122(2):198-205.

https://doi.org/10.1016/j.bja.2018.09.027

\section{PECULIARITIES OF ANESTHESIA \\ IN HEART VALVE PATHOLOGY}

E. Gudavičiūtė, R. Vasiliauskaitė logy.

Keywords: anesthesia, cardiac surgery, cardiac valves patho-

Summary

The spread and severity of heart valve disease constantly increases with age, increasing the demand for heart valve surgery in aging populations. The goals of hemodynamic differ with va- rious valve pathologies. Therefore, in this study, scientific sources analyzing peculiarities of anesthesia with differing heart valve pathologies, as well as hemodynamic goals relating to these pathologies shall be reviewed and discussed. The search of literary sources was done in medical databases such as PubMed, UpToDate and Medscape. Articles, matching the topic of the study, published in English between 2015 and 2020 were used in this review. This study shows that targeted heart contraction rate differs with various valve pathologies. Also, with the presence of aorta valve stenosis, it is recommended to avoid hypovolemia, conversely, in the presence of aorta and mitral valve prolapse hypervolemia is to be avoided. With mitral valve stenosis, both hypo- and hypervolemia should be avoided. Etomidate may be selected as an induction agent in patients with cardiogenic shock, hemodynamic instability, critical coronary artery disease, severe aortic stenosis, or severe cardiomyopathy. Patients with critical aortic stenosis or severe ventricular dysfunction require special care to titrate at lower doses. While performing heart surgery, the demands for anesthesia differ greatly, therefore it is necessary to correct the depth of anesthesia often.

Correspondence to: evelina.gudavic@gmail.com

Gauta 2021-05-05 